\title{
Localization and treatment of small and large bowel bleeding
}

RICHARD H HUNT, FRCP, FRCP(Edin), FRCPC, FACG

RH HUNT. Localization and treatment of small and large bowel bleeding. Can J Gastroenterol 1992;6(3):169-175. Bleeding from the small or large bowel may present a diagnostic dilemma for the clinician, requiring careful consideration and multidisciplinary consultation before the problem is located. Careful selection of the appropriate investigations in the most logical order is important to minimize delay to diagnosis, inconvenience, discomfort and risk to the patient and costs to health care delivery.

Key Words: Angiography, Diagnosis, Endoscopy, Gastrointestinal bleeding, Intervention

\section{Localisation et traitement de l'hemorragie au niveau du petit ou du gros intestin}

RÉSUMÉ: Les saignements originant du petit ou du gros intestin peuvent représenter pour le clinicien un dilemme au plan du diagnostic et requerra parfois un examen attentif, voire même une consultation entre spécialistes de diverses disciplines afin de bien situer le problème. Pour éviter tout retard de diagnostic, il convient de choisir les épreuves diagnostiques et de bien les classer chronologiquement. Cela abrégera l'inconfort et réduira le risque auxquels le patient est soumis tout en abaissant les coûts imposés au système de santé.

Division of Gastroenterology, McMaster University Medical Centre, Hamilton, Ontario Correspondence and reprints: Dr RH Hunt, Professor and Head, Division of Gastroenterology, McMaster University Medical Centre, 1200 Main Street West, Hamilton, Ontario L8N 325
B LEEDING FROM THE SMALL OR large bowel may present a diagnostic dilemma for the clinician which may require careful consideration and multidisciplinary consultation before the problem is located. Careful selection of the appropriate investigations in the most logical order is important to minimize the delay to diagnosis, the inconvenience, discomfort and risk to the patient and the costs to health care delivery. This paper reviews the approach to obscure bleeding from the large and small bowel, highlighting the different diagnostic modalities available and their optimal application.

\section{DIAGNOSIS}

Acute lower gastrointestinal bleeding: Massive hemorrhage from the large bowel is less common than from the upper gastrointestinal tract, but always presents the clinician with a difficult management problem (1-7). The signs 
of circulatory shock are invariably present and require urgent replacement of circulating blood volume and central venous pressure monitoring.

Immediate physical examination of the gastrointestinal tract should be a rectal examination and a rigid proctosigmoidoscopy to exclude hemorrhoids, fissure, fistula or a rectal lesion. This should be performed without preparation although copious blood clots should be evacuated through the instrument and the mucosa may need to be swabbed with cotton wool for adequate visualization. Nasogastric aspiration should exclude blood in the stomach, but a negative aspirate for blood should not be taken as an absolute exclusion of upper gastrointestinal bleeding (upper gastrointestinal endoscopy must always be considered). Routine hematology should also include a platelet count and coagulation profiles.

Barium enema should be avoided in the emergency situation because it prevents subsequent early colonoscopy or arteriography and makes surgery less easy. In most instances, severe colonic bleeding is episodic and self-limiting, although this period without bleeding may be temporary. Colonoscopy should be considered as the emergency diagnostic procedure of choice once the patient's condition is stabilized and bleeding has ceased $(1-3,8,9)$. The cathartic effect of blood in the colon usually removes solid stool and a balanced electrolyte bowel preparation (such as Golytely, Baxter), which may be given via a nasogastric tube, is the only preparation required. A repeat rigid sigmoidoscopy to remove any residual blood clots from the rectum is wise just before intubation with the colonoscope.

When colonoscopy is negative and bleeding continues, selective angiography of the superior and inferior mesenteric arteries and the coeliac axis should be performed in that order. Experimentally, this technique can detect bleeding rates as low as $0.5 \mathrm{~mL} / \mathrm{min}$, although intermittent bleeding and technical problems may limit success.

Obscure gastrointestinal bleeding: Obscure gastrointestinal bleeding pre- sents a management dilemma and usually is defined as persistent chronic blood loss despite normal endoscopic and $\mathrm{x}$-ray investigation (10-12).

The source of blood loss may be obscured at the initial endoscopic examination by bleeding, blood clot or (more rarely) contrast medium. A lesion may be identified but not be considered the source of blood loss; it may be rare (of subtle appearance or merely unrecognized by the endoscopist) or inaccessible to endoscopic or radiological diagnosis. The increasing availability of sophisticated angiographic techniques, isotope scanning and newer endoscopic techniques has increased the diagnostic yield in this perplexing condition.

Lesions that may cause obscure bleeding: Lesions in the small bowel are particularly inaccessible and radiological techniques have not been rewarding. Lesions which may be a source of blood loss include a Meckel's diverticulum, idiopathic ulceration, Crohn's disease, ischemia, vascular abnormalities, enteric duplication, metastatic tumours and primary malignancy (such as carcinoma, lymphoma, leiomyosarcoma or benign lipoma), leiomyoma, carcinoids or alternatively secondary metastases most typically from a malignant melanoma or invasion from a colonic or pelvic primary. The approach to diagnosis is shown below.

Small bowel studies: Small bowel studies may demonstrate large lesions such as tumours or diverticula with strictures usually well-delineated. Small bowel radiology may be enhanced by the techniques of enteroclysis or small bowel enema. Recently the combination of this technique with ingestion of methyl cellulose has improved visualization; however, these techniques seldom identify small mucosal lesions.

Radionuclide scans: Bleeding scans include three basic techniques: ${ }^{99}$ technetium-sulphur colloid (best reserved to identify the site of active bleeding since it is rapidly cleared by the liver and spleen), technetium-labelled red cell scan (which has the advantage that repeat scans of the abdomen may be made over time to detect pooling of blood from slow or intermittent bleed- ing which is helpful to determine the value of proceeding to angiography); and ${ }^{99}$ technetium pertechnetate scan (used to detect the ectopic gastric mucosa found in a Meckel's diverticulum). Approach to diagnosis: History and physical, repeat upper gastrointestinal endoscopy and colonoscopy, small bowel radiology, bleeding scans, arteriography, enteroscopy and peroperative endoscopy at laparotomy should be performed.

Angiography: Arteriography may be useful if bleeding is occurring at a fast enough rate, probably about $3 \mathrm{~mL} / \mathrm{min}$, but may also be useful to outline the features of angiodysplasia when a vas. cular tuft is seen (in about 75\% of cases), especially together with an early draining vein and enlarged submucosal vein, or a tumour (13). If active bleeding is seen, selective arterial catheterization provides the possibility to infuse vasopressin or to embolize the vessel either as a holding measure or as definitive treatment. Repeated examination may be useful if the initial examination is negative $(14,15)$.

Endoscopic techniques: Upper gastrointestinal endoscopy and colonoscopy should always be repeated, and at upper gastrointestinal endoscopy it is important to intubate the small bowel to the ligament of Treitz - best accomplished using a pediatric colonoscope.

Missed lesions: At endoscopy, vascular lesions may be missed easily anywhere in the gastrointestinal tract, especially the small 'red spot' lesions in the stomach or the 'watermelon' lesion which involves the gastric antrum and may be misdiagnosed as gastritis. Both the classical Dieulefoy lesion high on the posterior lesser curvature of the stomach or a small fundal leiomyoma are typically missed.

In the right colon, angiodysplasia lesions may be missed due to overlying stool, small lesions lying beyond a fold or when excessive air insufflation at colonoscopy results in the colonic intraluminal pressure being greater than the pressure in the mucosal arteriovenous malformation. It may take several minutes for a vascular ab. normality to reperfuse and become visible again after blanching in this way. 
Small bowel enteroscopy: Direct vision of the small bowel has been difficult, although possible, using a transintestinal string or by peroperative examination with the long colonoscope at laparotomy. It may now be undertaken with the naso-enteric Sonde small intestinal fibrescope (Olympus) (16-18) which has a diameter of $5 \mathrm{~mm}$, length of $2.75 \mathrm{~m}$, and channels for air/ carbon dioxide insufflation and inflation of the terminal Sonde balloon. The angle of vision is $90^{\circ}$ but there is no tip control, differential flexibility or instrument channel. The instrument is passed transnasally and is 'piggybacked' through the pylorus to the duodenojejunal flexure using a pediatric colonoscope passed conventionally, through which blunt forceps are passed to pick up a silk suture tied to the tip of the enteroscope. The balloon is then inflated and metoclopramide given to facilitate intubation. Upon withdrawal, carbon dioxide is insufflated and manual abdominal compression is used to optimize visualization.

Results with this instrument have been described by Lewis and Waye $(16,17)$ in 60 patients with obscure gastrointestinal bleeding. The average procedure time was $6 \mathrm{~h}$ and the enteroscope passed to ileum or beyond in $77 \%$ of patients. The source of blood loss was identified in 20 patients $(33 \%)$.

Rademaker and Hunt (18) similarly diagnosed six of 16 patients; however, examination of the small bowel was complete in only eight procedures limited examinations resulted from technical difficulties including looping of the enteroscope in the stomach, and obstruction to passage in the small bowel at anastomoses or from adhesions due to previous surgery. Several other problems have been encountered with the balloon which has ruptured, failed to deflate or intussuscepted over the lens in three separate incidents. The average time for the procedure has decreased with author experience and is now about $6 \mathrm{~h}$. The authors made a diagnosis in about one-third of patients.

Currently the Sonde small intestinal fibrescope has no capacity for instrumentation since there is no biopsy channel. There is no control of the dis- tal tip and the instrument cannot be re-advanced, reducing visualization of the mucosa to only about $50 \%$ of the mucosal surface. This can be maximized by inflation of the bowel lumen with carbon dioxide which is absorbed rapidly and causes less discomfort than air, and manual abdominal palpation to 'ballot' the bowel around the distal tip and lens. The author routinely videotapes examination with the OTV system so that any suspicious areas can be 're-examined' as many times as is considered necessary.

The author has found the Sonde small intestinal fibrescope enteroscope valuable in patients with obscure gastrointestinal bleeding. It has proven safe and well-tolerated, and provides an overall diagnosis in onethird of patients; because it is expensive in cost and time, its use should be limited to major centres.

\section{INTERVENTIONAL ENDOSCOPY FOR GASTRO. INTESTINAL BLEEDING} Injection for nonvariceal lesions: The injection techniques for upper gastrointestinal lesions advocated by Sohendra (19) are simple and cheap. The use of $1 \%$ polidocanol - either alone or preceded by 1:10000 adrenaline - has been most frequently used, although $100 \%$ ethanol or hypertonic saline may be substituted for polidocanol. The techniques described are clearly effective in arresting acute hemorrhage from the upper gastrointestinal tract, but randomized controlled trials have not yet compared these techniques with other methods of endoscopic hemostasis. There has been no reported significant experience of these injection techniques in the colon. Indeed, the relative thinness of the colonic wall would argue against the safety of this approach.

However, in cases of post polypectomy bleeding, injection into the residual stalk may be attempted if snaring and tightening the snare wire without the application of current has failed.

BICAP and heater probes: Extensive animal work and controlled trials in upper gastrointestinal bleeding have been undertaken with BICAP and heater probes, which have improved the outcome in patients with active upper gastrointestinal bleeding. There have been no reports of the use of these modalities in patients with colonic bleeding.

Laser treatment: Controlled trials of laser therapy for upper gastrointestinal bleeding have shown a reduction in rebleeding and need for surgery, and a single study showed a reduction in mortality for laser-treated patients (20). Despite controversy over the value of laser therapy for acute bleeding in the upper gastrointestinal tract, it is reasonable to conclude that for patients who were eligible for (and consented to) enter laser trials, hemostasis could be achieved, and re-bleeding, operation and mortality was reduced. Laser experience in the colon has been extensive for the treatment of vascular abnormalities (vide infra) and there has been an initial report of successful treatment of eight patients with bleeding from severe proctitis consequent on radiation injury (21). Treatment with the Nd:YAG laser significantly reduced transfusion requirements and hospital admissions, and the effect was long-lasting. Vascular abnormalities: Vascular abnormalities are increasingly recognized throughout the gastrointestinal tract and lesions are commonly found to be the source of blood loss from the stomach and colon. Bleeding may vary from slow occult blood loss to massive hemorrhage with hypovolemic shock $(9,22)$. The pattern of bleeding may vary both within and between individuals but, even when severe, each episode is usually self-limiting. Bleeding often is bright red or maroon in colour from colonic or small bowel lesions, but a history of tarry stools may also be obtained. Typically patients with colonic vascular ectasias often give a history of one or more operations from a diagnosis such as duodenal ulcer or diverticular disease.

Angiodysplasia of the right colon and cecum is the most commonly encountered vascular abnormality in the gastrointestinal tract. Lesions have been recognized by radiologists since the initial report by Margulis et al (23) and the development of selective mes- 
enteric angiography $(6,24-27)$. Colonoscopic diagnosis of the lesions of angiodysplasia were first reported in 1976 by Skibba et al (28) and by Rogers and Adler (29), and are now recognized as an important cause of colonic bleeding which should be sought exhaustively by the colonoscopist (9), although the frequency with which this diagnosis is made recently has been questioned (30).

The endoscopic appearance of a vascular abnormality depends upon its nature. Angiodysplasia lesions in the right colon are cherry red in colour and usually about $5 \mathrm{~mm}$ in size (although they can be larger and more extensive). There is usually an elevated dilated central vessel which, to the endoscopist, is distended visibly with radiating peripheral vessels.

Meticulous cleansing of the colon is essential when colonoscopy is performed in cases where angiodysplasia is suspected (31); since this lesion represents a low pressure capillary arteriovenous communication, excessive inflation of the cecum and right colon (by introduction of air from the colonoscope) can result in the blanching of the lesion which then becomes invisible (vide supra). It may take several minutes for the lesion to refill and the endoscopist should deflate the right colon periodically during the examination if angiodysplasia is suspected. Diagnosis of angiodysplasia may be made at operation if a careful examination of the mucosal surface of the colon is made immediately after segmental resection (32). Although angiomatous lesions may produce changes on the serosal surface of the colon at surgery, this is not the case with angiodysplasia. This emphasizes the importance of defining the extent of angiodysplasia by both colonoscopy and angiography when surgery is contemplated.

In patients with a history of gastrointestinal bleeding, fibreoptic endoscopy should be undertaken before selective angiography is considered this will often lead to the diagnosis, especially when the endoscopist has a high index of suspicion and makes a meticulous search for a lesion. Selective angiography may still be useful as a complementary investigation to con- firm the extent of a lesion and exclude any additional lesions. True comparative studies between colonoscopy and angiography have been few. In a study from the Massachusetts General Hospital (33), colonoscopy had a sensitivity of $81 \%$, but the authors assumed that angiography had a sensitivity of $100 \%$. In a study from the Hammersmith Hospital (34), a sensitivity of $68 \%$ was found for colonoscopy, but examination to the cecum was complete in only $75 \%$ of cases.

If these investigations do not provide a diagnosis, laparotomy may be considered in the patient who continues to bleed. A positive diagnosis, however, was made by a laparotomy in only half the cases in one pediatric series (35). With the variety of diagnostic methods now available, most lesions may be detected without surgery. Laparotomy is best reserved to manage lifethreatening hemorrhage rather than to identify an otherwise undetected lesion (7). If diagnostic laparotomy is performed, it is wise to consider the use of intra-operative endoscopy. Peroperative colonoscopy of the large bowel extended through to the small bowel, or the use of a long colonoscope or enteroscope through the small bowel from above may be valuable to transilluminate the intestinal wall in a search for vascular abnormalities. The surgeon views from the serosal aspect and pleats the bowel segments over the colonoscope, which is passed under direct vision by the endoscopist who views the bowel intralumenally $(36,37)$.

\section{TREATMENT}

When bleeding is severe, initial efforts are directed towards resuscitation before identifying the site and cause of bleeding. Although most gastrointestinal vascular abnormalities can present with bleeding, many episodes are self-limiting or lead to occult blood loss. Emergency surgery may be necessary for life-threatening hemorrhage, but because of associated increased morbidity and mortality, every attempt should be made to establish a diagnosis so that definitive elective surgery can be planned.

Limited angiodysplasia lesions in the cecum and right colon $(9,38)$ and telangiectasia in the stomach $(39-41)$ have been treated at endoscopy by electrocoagulation using the Williams coagulation forceps $(9,21,38,42)$, a monopolar button electrode (40), the BICAP, the heater probe $(43,44)$ or laser therapy (45-52). However, most extensive vascular abnormalities will require resection.

The results of electrocoagulation have been promising $(4,9,21,38,40,46)$, especially for angiodysplasia of the right colon and cecum which obviates the need for major surgery in an elderly high risk population. For these lesions, the coagulation forceps $(21,38,42,52)$ are preferable to the button electrode which is more likely to result in perforation of the thin-walled cecum. Several authors report good results and a very low complication rate with hot biopsy forceps $(9,21,38,46,47,52)$. The coagulation biopsy forceps are placed at the periphery of the lesion and gently withdrawn until the mucosa is 'tented' towards the lumen of the colon $(9,38)$. This pulls the mucosa and submucosa away from the deeper layers of the colonic wall (which is especially thin in the cecum and right colon) and decreases the very real risk of transmural coagulation or perforation. The apex of the 'tent' is pulled asymmetrically over the centre of the lesion to enhance coagulation in the mucosa and submucosa at the site of angiodysplasia. Coagulation usually is performed at no more than $25 \mathrm{~W}$ and power is applied in very short bursts to produce a wellcontrolled, small and superficial coagulation. Biopsies can be taken and these may confirm the diagnosis his. tologically, although this may increase the risk of immediate or delayed perforation $(21,38)$ and photographic documentation probably is sufficient confirmation of the endoscopic diagnosis.

The heater probe and BICAP are two new, portable and economical ways to achieve thermal coagulation by contact $(43,44)$. The $10 \mathrm{~F}$ heater probe provides a larger surface and better coagulation effect. Gentle pressure is applied to the periphery of the lesion until blanching is seen; subsequently, greater pressure can be applied to the central vessels. The coaptive properties 
of these devices favour coagulation and sealing of the small vessels as they are compressed. Little or no experience of these techniques for colonic bleeding has yet been published.

Laser photo-coagulation with the argon ion or $\mathrm{Nd}$ :YAG has been widely used $(44,46,48-51)$ and general experience has shown that Nd:YAG at a power setting of 70 to $85 \mathrm{~W}$ should be used for vascular lesions (the light guide at 1 to $1.5 \mathrm{~cm}$ from the lesion); power should be delivered in short and rapid bursts, with up to 15 pulses for larger lesions to produce blanching around the lesion without vaporization. The coagulation should be just around the periphery of the lesion before the central area is coagulated. Particular difficulties may arise with access to lesions in the duodenum or colon when they lie on folds distal to the endoscope; these may be missed altogether or inadequately coagulated.

Additional concerns with laser therapy have been complications and cost. One study reported a complication rate of $6 \%$ with cecal lesions but this may be related to the distension of the right colon due to carbon dioxide insufflation (50). However, coaptive electrocautery probes are as effective as argon ion laser for gastric angiodysplasia and they are cheaper (44). Contact microprobes have recently been developed for the Nd:YAG laser (53) which reduce the power requirements to between 5 and $15 \mathrm{~W}$ and require little carbon dioxide, thus potentially reducing the costs of laser therapy. One early report (46) using such therapy suggests better results for lesions which are otherwise inaccessible. The place of laser treatment for vascular abnormalities is promising, with rebleeding occurring in $18 \%$ of patients in one study (50). However, all patients with

\section{REFERENCES}

1. Swarbrick ET, Hunt RH. Rectal bleeding. In: Hunt RH, Waye JD, eds. Colonoscopy Techniques, Clinical Practice and Color Atlas. London: Chapman and Hall, 1981:267-88.

2. Leicester RJ, Hunt RH. Lower gastrointestinal haemorrhage. In: Hunt PS, ed. Gastrointestinal Haemorrhage. Melbourne: Churchill Livingstone,
Osler-Rendu-Weber syndrome or with angiomas associated with coagulation disorders due to von Willebrand's disease had a recurrence of bleeding after laser therapy. Recurrence occurred in $67 \%$ in a recent large experience reported from the Netherlands (54); in this study, complications occurred in $9 \%$ of patients (all had colonic angiodysplasia and some were diagnosed with serosal burns, carbon dioxide distension and post treatment bleeding). Nevertheless, this approach was considered by the author to have provided an indispensable approach to the problem of angiodysplasia, especially in elderly or inoperable patients. Analysis of long term follow-up data in 57 patients with vascular abnormalities showed a statistically significant reduction of rebleeding and transfusion requirements after laser therapy compared with a similar pretreatment control period.

With all the methods discussed, many patients will require more than a single treatment session $(9,21,46,50$, 51). When vascular abnormalities are too numerous or extensive, patients should undergo upper gastrointestinal endoscopy, colonoscopy and triple vessel angiography prior to surgery to assess the full extent of the lesion, and peroperative endoscopy may be useful to define the point of resection.

Therapeutic angiography: The development of steerable catheters has transformed diagnostic selective visceral angiography into an important potential therapeutic technique in patients with severe hemorrhage from the gastrointestinal tract. Diagnosis may be achieved with control of hemorrhage by vasopressin infusion in up to 75 or $80 \%$ of patients with bleeding in the territory of the left gastric or celiac arteries. In the pyloroduodenal region,

1986:123-34

3. Somers S, Hunt RH. Acute colonic haemorrhage. In: Bouchier IAD, Allan RN, Hodgson HJF, Keighley MRB, eds. Textbook of Gastroenterology. London: WB Saunders, 1984:308-17.

4. Hunt RH. Angiodysplasia of the gut. In: Bouchier IAD, Allan RN, Hodgson HJF, Keighley MRB, eds. Textbook of Gastroenterology. London: WB the success rate falls to between 55 and $65 \%$, while at other sites in the gastrointestinal tract, experience is somewhat less and figures are therefore less reliable. In addition to vasopressin infusion, embolization is also possible using gelfoam, ivalon particles, liquid adhesives or detachable balloons. Experience with these techniques is still limited and success is dependent largely upon selective catheterization of the bleeding vessel since there is a real risk of infarction of the bowel wall, gallbladder, liver or spleen.

Despite the significant advances in both diagnostic and therapeutic angiography, these procedures should only be undertaken if endoscopy is unavailable or has failed to make a diagnosis. Furthermore, therapeutic angiography is of most benefit in arresting initial hemorrhage at the time of diagnosis or may be attempted in patients who are considered poor surgical candidates or those who develop bleeding as a post surgical complication. Angiographic techniques to infuse vasopressin or to perform transcatheter embolization have also been used. Surgical resection for Meckel's diverticulum, duplications, malignancy and congenital vascular abnormalities are successful when the diagnosis has been made and should be considered in good risk patients. Patients with bleeding from ulcerative colitis require subtotal or total colectomy while those with Crohn's disease may only require a limited resection. In elderly patients, differentiation between angiodysplasia and diverticular disease must be made and will dictate where the segmental, right hemicolectomy or subtotal colectomy should be undertaken. Emergency subtotal colectomy carries a high morbidity and significant mortality, and is considered as a last resort.

Saunders, 1984:259-66

5. Hunt RH. Rectal bleeding. Clin Gastroenterol 1978;3:719-40.

6. Giacchino JL, Geis WP, Pickleman JR, Dado DR, Hadcak WE, Frceark RJ

Changing perspectives in massive lower intestinal bleeding. Surgery 1979;86:368-76.

7. Boley SJ, Brandt LJ, Frank MS. Severe lower intestinal bleeding; diagnosis and 
treatment. Clin Gastroenterol 1981;10:65-91

8. Jensen DM, Machicado GA. Diagnosis and treatment of severe hematochezia. The role of urgent colonoscopy after purge. Gastroenterology 1988;95:1569-74.

9. Howard OM, Buchanan JD, Hunt RH. Angiodysplasia: Experience of 26 cases Lancet 1982;ii: $16-9$.

10. Peterson WL. Obscure gastrointestinal bleeding. Med Clin North Am 1988;72:1169-76.

11. Spiller R, Parkins RA. Recurrent gastrointestinal bleeding of obscure origin. $\mathrm{Br}$ J Surg 1983;70:849-93.

12. Thompson JN, Salem RR, Hemingway AP, et al. Specialist investigation of obscure gastrointestinal bleeding. Gut, 1987;28:47-51

13. Ng BL, Thompson JN, Adam A, et al. Selective visceral angiography in obscure postoperative gastrointestinal bleeding. Ann R Coll Surg Engl 1987;69:237-40.

14. Lau WY, Fan ST, Wong SH, et al. Preoperative and intra-operative localization of gastrointestinal bleeding of obscure origin. Gut 1987:28:869-77.

15. Lau WY, Ngan H, Chu KW, Yuen WK. Repeat selective visual angiography in patients with gastrointestinal bleeding of obscure origin. Br J Surg 1989; 76:226-9.

16. Lewis BS, Waye JD. Chronic gastrointestinal bleeding of obscure origin: Role of small bowel enteroscopy. Gastroenterology 1988;94:1117-20.

17. Lewis BS, Waye JD. Total small bowel enteroscopy. Gastrointest Endosc $1987 ; 33: 435-8$

18. Rademaker J, Hunt RH. Experience with the SSIF enteroscope in patients with suspected small bowel disease. J Gastroenterol Hepatol. (In press)

19. Sohendra N. Endoscopic ligation techniques for control of gastro-duodenal haemorrhage. In: Bennett JR, Hunt RH, eds. Therapeutic Endoscopy and Radiology of the Gut. London: Chapman and Hall, 1990:162-5.

20. Swain CP, Bown SG, Salmon PR, et al. Controlled trial of Nd:YAG laser photocoagulation for bleeding peptic ulcer. Lancet 1986;1:113-6.

21. Alexander TJ, Dwyer RM. Endoscopic Nd:YAG laser treatment of severe radiation injury of the lower gastrointestinal tract: Long term follow up. Gastrointest Endosc 1988;34:407-11

22. Hunt RH. Angiodysplasia of the colon. In: Salmon PR, ed. Advances in Gastrointestinal Endoscopy. London: Chapman and Hall, 1984:97-114.
23. Margulis AR, Heinbecker P, Bernard HR. Operative mesenteric arteriography in the search for the site of bleeding in unexplained gastrointestinal bleeding. Surgery 1960;48:534-9.

24. Allison DJ, Hemingway AP, Cunningham DA. Angiography in gastrointestinal bleeding. Lancet 1982; ii:30-3

25. Baum S, Nusbaum M, Blakemore WS, Finkelstein AK. The preoperative radiographic demonstration of intra-abdominal bleeding from undetermined sites by percutaneous selective coeliac and superior mesenteric arteriography. Surgery 1965:58:797-805

26. Tarin D, Allison DJ, Modlin IM, Neale G. Diagnosis and management of obscure gastrointestinal bleeding. $\mathrm{Br}$ Med ] 1978; vol:751-4

27. Hunt RH. Angiodysplasia of the gut. In: Bennett JR, Hunt RH, eds. Therapeutic Endoscopy and Radiology of the Gut. Baltimore: Williams and Wilkins, 1990:178-89.

28. Skibba RM, Hartong WA, Mantz FA, Hindthorn DR, Rhodes JB.

Angiodysplasia of the caecum: Colonoscopic diagnosis. Gastrointest Endose 1976;22:177-9.

29. Rogers BHG, Adler F. Hemangiomas of the caecum. Gastroenterology 1976;71:1079-82.

30. Danesh BJZ, Spiliadis C, Williams CB, Zambamtas CM. Angiodysplasia - an uncommon cause of colonic bleeding: Colonoscopic evaluation of 1050 patients with rectal bleeding and anaemia. Int J Colorectal $1987 ; 2: 218-22$

31. Nagy GS. Preparing the patient. In: Hunt RH, Waye JD, eds. Colonoscopy Techniques, Clinical Practice and Colour Atlas. London: Chapman and Hall 1981:19-26.

32. Heald RJ, Ray JE. Vascular malformations of the intestine: An important cause of obscure gastrointestinal haemorrhage. South Med J 1974;67:33-8.

33. Richter JM, Hedberg SE, Athanasoulis CA, et al. Angiodysplasia: Clinical presentation and colonoscopic diagnosis. Dig Dis Sci 1984:29:481-5

34. Salem RR, Wood CB, Rees HC, et al. A comparison of colonoscopy and selective visceral angiography in the diagnosis of angiodysplasia. Ann R Coll Surg Engl 1985;67:225-6.

35. Shandling B. Laparotomy for rectal bleeding. Paediatrics 1965;35:787-93

36. Bowden TA, Hooks VH, Mansberger AR. Intraoperative gastrointestinal endoscopy. Ann Surg 1979;191:680-7.

37. Forde KA. Intraoperative colonoscopy.
In: Hunt RH, Waye JD, eds Colonoscopy Techniques, Clinical Practice and Colour Atlas. London: Chapman and Hall, 1981:189-98.

38. Rogers BHG. Endoscopic diagnosis and therapy of mucosal vascular abnormality of the gastrointestinal tract occurring in elderly patients and associated with cardiac, vascular and pulmonary disease. Gastrointest Endosc 1980;26:134-8.

39. Weaver GA, Alpern HD, Davis JS, Ramsey WH, Reichelderfer M. Gastrointestinal angiodysplasia associated with aortic valve disease: Part of a spectrum of angiodysplasia of the gut. Gastroenterology 1979;77:1-11.

40. Colin-Jones DG. Vascular malformations of the upper GI tract. In: Salmon PR, ed. Advances in Gastrointestinal Endoscopy. London Chapman and Hall, 1984

41. Farup PG, Roseland A, Stray N, Pytte R, Valnes K, Rand AA. Localized telangiopathy of the stomach and duodenum diagnosed and treated endoscopically. Endoscopy 1981;12:1-6

42. Williams CB. Diathermy-biopsy: A technique of endoscopic management of small polyps. Endoscopy 1973;5:215-8.

43. Johnston J, Rawson S, Namihira Y. Experimental comparison of heater probe and BICAP for endoscopic treatment of gastrointestinal bleeding. Gastrointest Endosc 1985;31:155-6.

44. Jensen DM, Machicado GA, Slipa ML. Argon laser versus heater probe on BICAP for control of severe ulcer bleeding. Gastrointest Endosc 1984;30:134

45. Fruhmorgen P, Bodem F, Reindenbach HD, Kaduk B, Demling L. Endoscopic laser coagulation of bleeding gastrointestinal lesions with report of the first therapeutic application in man. Gastrointest Endosc 1976;23:73-5

46. Marcon NE. The endoscopic management of angiodysplasia. Acta Endoscopica 1987;17:109-19.

47. Marcon NE, Haber GB, Kortan PP, Cohen L. Gastro-duodenal angiodysplasia - an under diagnosed cause of upper gastrointestinal bleeding.Gastrointest Endosc 1985:31:167

48. Kiefhaber P, Nath G, Maritz K. Endoscopical control of massive gastrointestinal haemorrhage by irradiation with a high power Nd:YAG laser. Progress in Surgery 1977;15:140

49. Rutgeerts P, Vantrappen G, Geboes K Broeckaerk L. Nd:YAG laser photo-coagulation for haemostasis of gastrointestinal non-variceal 
haemorrhage. Gastroenterology 1983;21:263-7.

50. Rutgeerts P, Van Gompel F, Geboes K, Vantrappen G, Broekaert L, Coremans G. Long term results of treatment of vascular malformations of the gastrointestinal tract by $\mathrm{Nd}: \mathrm{YAG}$ laser photo-coagulation. Gut 1985;26:586-93.

51. Bown SG, Swain CP, Storey DW, et al. Endoscopic laser treatment of vascular abnormalities of the upper gastrointestinal tract. Gut 1985;26:1338-48.

52. Rogers BHG. The electrocoagulation forceps is ideal for the diagnosis and management of small vascular abnormalities of the caecal area. Gastrointest Endosc 1985;31:222-4.

53. Tsunekawa H, Morise K, Ilzuka A, et al. Studies on the application of the newly developed laser microprobes for the Nd:YAG laser. In: Waidelich E, Kiefhaber $P$, eds. Proceedings of the 7th International Congres with 2nd International Nd:YAG Laser conference. New York: Springer Verlag, 1985:360-6.

54. Mathus-Vliegen EMH. Laser treatment of intestinal vascular abnormalities. Int J Colorect Dis $1989: 4: 20-5$. 


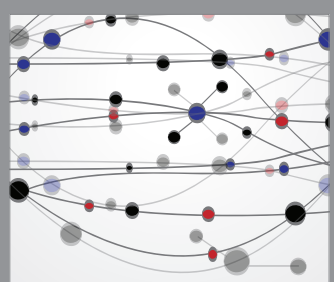

The Scientific World Journal
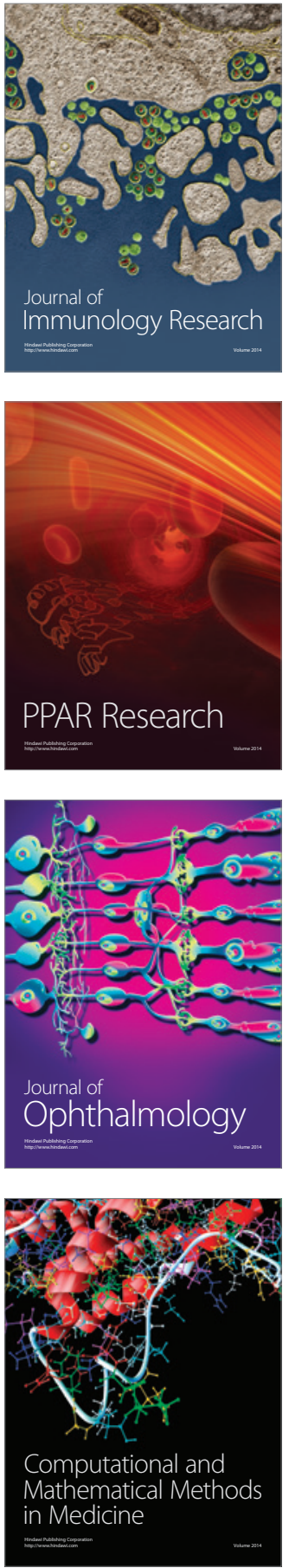

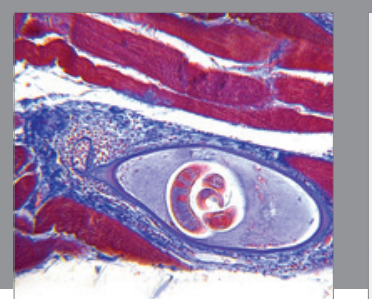

Gastroenterology Research and Practice

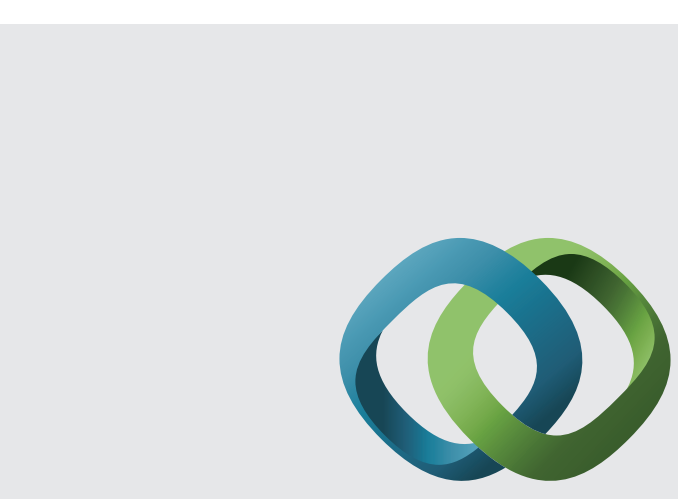

\section{Hindawi}

Submit your manuscripts at

http://www.hindawi.com
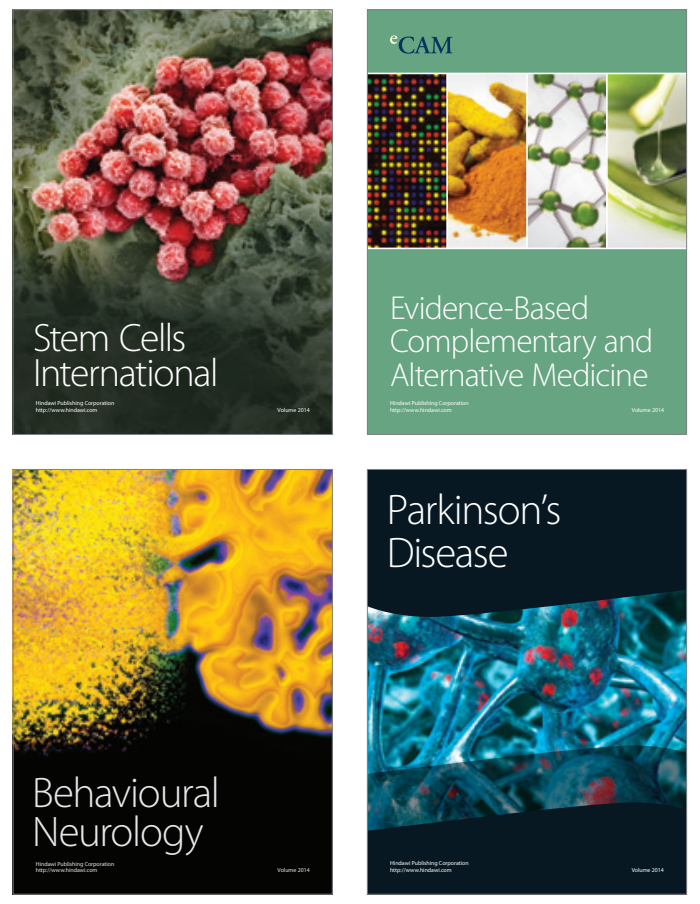
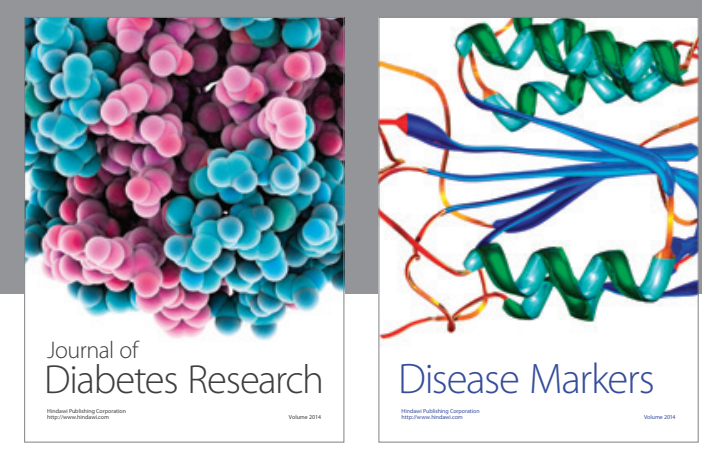

Disease Markers
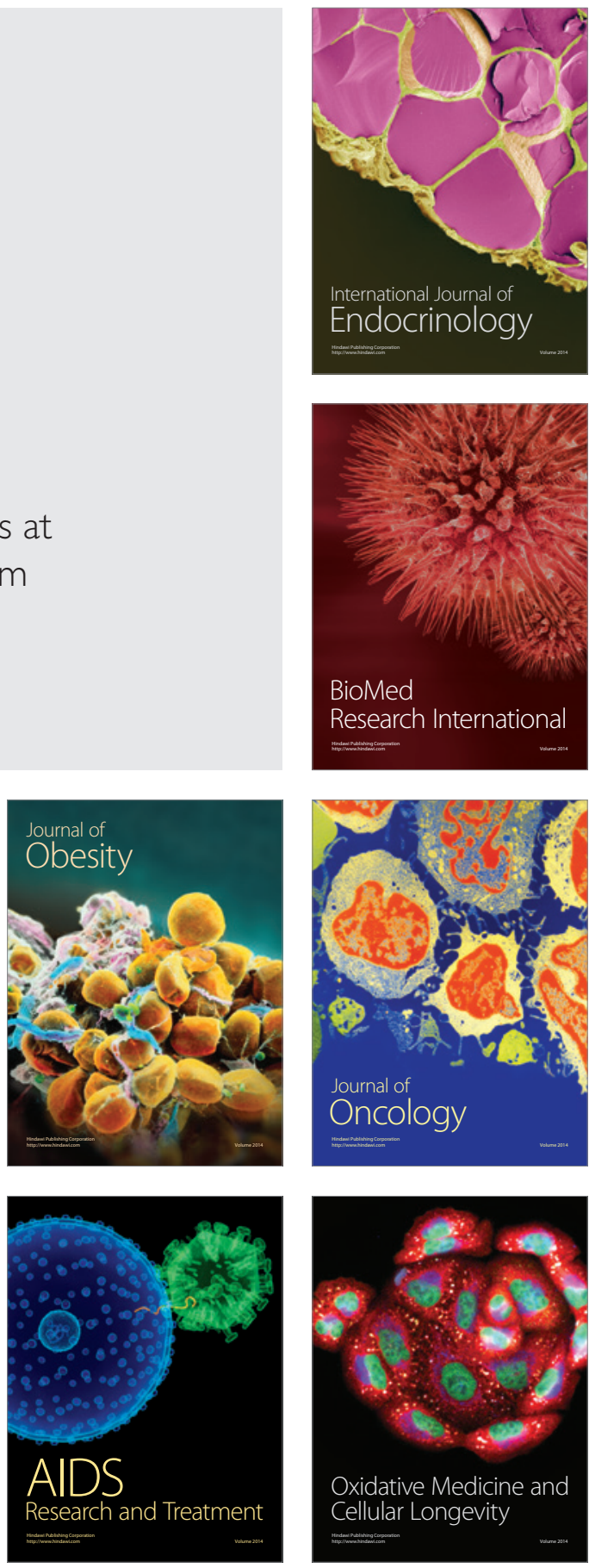